\title{
Comparison between oxytocin, ergometrine and misoprostol in active management of the third stage of labour: a randomized controlled trial
}

\author{
Abubaker Y. H. Abdel Rahim', Mohamed A. A Gadir E. Ounsa², Rayan G. Albarakati², \\ Elsadig Y. Mohamed ${ }^{4 *}$, Sawsan M. Abdalla ${ }^{4}$
}

\author{
${ }^{1}$ Department of Obstetrics and Gynecology, MOH, Sudan \\ ${ }^{2}$ Department of Obstetrics and Gynecology, The National Ribat University, Sudan \\ ${ }^{3}$ Department of Obstetrics and Gynecology, Majmaah University, Saudi Arabia \\ ${ }^{4}$ Department of Community Medicine, College of Medicine, Majmaah University, Saudi Arabia
}

Received: 22 March 2018

Accepted: 30 April 2018

\section{*Correspondence: \\ Dr. Elsadig Y. Mohamed, \\ E-mail: elsadigoo@gmail.com}

Copyright: (C) the author(s), publisher and licensee Medip Academy. This is an open-access article distributed under the terms of the Creative Commons Attribution Non-Commercial License, which permits unrestricted non-commercial use, distribution, and reproduction in any medium, provided the original work is properly cited.

\section{ABSTRACT}

Background: The aim of the present study was to compare the effectiveness of sublingual misoprostol, intravenous infusion of oxytocin, and intravenous infusion of Ergometrine in reducing blood loss during the third stage of labor. Methods: This is a no-random trial study conducted in in Ribat University Hospital, Khartoum among 150 laboring ladies with a healthy singleton pregnancy. After obtaining their written informed consent to participate in the study, they were randomly assigned to one of three possible treatment groups: $400 \mu \mathrm{g}$ of sublingual misoprostol; $10 \mathrm{IU}$ of intravenous infusion oxytocin; and $0.5 \mathrm{mg}$ of intravenous infusion of Ergometrine. Blood loss was estimated by weighing the collected blood and converting the weight to milliliters.

Results: The shortest mean duration of the third stage of labor was seen in patients who received misoprostol $(3.89 \pm 0.37 \mathrm{~min})$, followed by oxytocin $(4.6 \pm 0.9 \mathrm{~min})$, and Ergometrine $(5.45 \pm 0.9 \mathrm{~min})$. The lowest mean blood loss was seen in the patients who received $400 \mu \mathrm{g}$ misoprostol $(168.36 \pm 24.83 \mathrm{ml})$, followed by those who received $10 \mathrm{IU}$ oxytocin $(205.56 \pm 34.82 \mathrm{ml})$, and $0.5 \mathrm{mg}$ Ergometrine $(214.49 \pm 35.97 \mathrm{ml})$.

Conclusions: Present study showed that $400 \mu \mathrm{g}$ sublingual misoprostol was more effective than the conventional parenteral uterotonics in reducing the amount of the blood loss during the third stage of labor and has comparable effect to that of $10 \mathrm{IU}$ intravenous oxytocin in shortening the duration of third stage of labor. It also showed that the use of misoprostol reduces the need for extra-uterotonics and blood transfusion.

Keywords: Ergometrine and misoprostol, Oxytocin, Third stage of labor

\section{INTRODUCTION}

Most of the deaths and disabilities attributed to childbirth are avoidable, because the medical solutions are well known. Indeed, $99 \%$ of maternal deaths occur in developing countries that have an inadequate transport system, limited access to skilled care-givers, and poor emergency obstetric services. ${ }^{1}$
Postpartum hemorrhage, which may be due to presence of fibroids, is the most common cause of maternal mortality and it accounts for one-sixth of the maternal deaths world-wide. ${ }^{2}$ The optimal solution for the vast majority, if not all, of these tragedies is prevention, both before the birth, by assuring that women are sufficiently healthy to withstand postpartum hemorrhage should it occur, and at the time of the birth, by the use of active management of labor, a management strategy that 
unfortunately is dependent on circumstances and the availability of oxytocics. ${ }^{3}$

In rural areas of Kassala state - Sudan, a study found that $59.4 \%$ of the maternal mortality was due to direct obstetric causes, out of which, $26.3 \%$ were due to haemorrhage. ${ }^{4}$ Another study was done in Kassala, Sudan concluded that uterine atonia was the major cause of postpartum hemorrhage, and accordingly they recommended adopting active management of third stage to all deliveries regardless of the presence of risk factors. ${ }^{5}$

In a study conducted in Baroda, the researchers found that methylergometrine has the best uterotonic drug profile amongst the drugs used, strongly favoring its routine use as oxytocic for active management of third stage of labor. Misoprostol was found to cause a higher blood loss compared to other drugs and hence should be used only in low resource setting if other drugs are not available. $^{6}$

Active management of the third stage of labor (AMTSL)comprising administration of a uterotonics agent at delivery of the anterior shoulder or within a minute of delivery of the neonate, early cord clamping, and controlled cord traction of the placenta-has been proven conclusively in several large-scale randomized controlled studies to be more effective than expectant management in reducing postpartum haemorrhage., ${ }^{7,8}$

Despite considering it as a notorious drug due to the misuse, misoprostol, a synthetic prostaglandin E1 analog, has shown promise as an effective oxytocic agent. It has several benefits as it is affordable, cheap and stable at room temperature, has a shelf life of several years, and can be administered by multiple routes. ${ }^{9}$

The aim of the present study was to compare the effectiveness of $400 \mu \mathrm{g}$ of sublingual misoprostol, $10 \mathrm{IU}$ of intravenous infusion oxytocin, and $0.5 \mathrm{mg}$ of intravenous infusion Ergometrine and reducing blood loss during the third and fourth stages of labor.

\section{METHODS}

This randomized control trial was conducted at the National Ribat University Hospital, Khartoum, one of the tertiary hospitals in Sudan. A total of 150 women were targeted to be randomly assigned to one of three arms: $400 \mu \mathrm{g}$ of sublingual misoprostol; $10 \mathrm{IU}$ of intravenous infusion oxytocin; and $0.5 \mathrm{mg}$ of intravenous infusion Ergometrine. All patients with a healthy singleton pregnancy in spontaneous labor at term were considered for this study. Conditions for exclusion were: grand multiparity, intrauterine fetal demise, antepartum hemorrhage, multiple pregnancy, mal-presentation, cardiac disease, Rhesus-negative mother, hypertensive disorders, history of jaundice or hepatic impairment, history of heparin or aspirin administration, bleeding tendency and (hemoglobin $<9 \mathrm{~g} / \mathrm{dl}$ ).
Eight patients underwent caesarian sections and two were diagnosed as eclampsia and all ten cases were excluded from the study. Each patient was allocated using computer-generated random numbers, through a dynamic system which has been designed especially for this trial by (MM-TECH), one of the most competent IT development companies in Sudan.

On admission to the delivery room, women eligible for the study were informed about it, and a written informed consent to participate in the study was obtained from the patients, then the computer randomly selected which of the three groups to be allocated.

After a detailed history and examination, hemoglobin level was measured in all patients. Fetomaternal monitoring during the first and second stages of labor was carried out according to the standard guidelines. All deliveries were attended in the delivery room by the investigator or by one of two well-trained members of the working team on duty.

At delivery of the anterior shoulder, the 2 sublingual misoprostol tablets $200 \mu \mathrm{g}$ each or one of the intravenous injections, oxytocin $10 \mathrm{IU}$ or Ergometrine $0.5 \mathrm{mg}$, were administered to the patient. The parenteral drugs were diluted in $100 \mathrm{ml}$ normal saline infusion and administered at 25 drops/minute (over 1 hour).

Following delivery of the neonate, the umbilical cord was clamped and cut, and the neonate was handed to the pediatrician. Linen soiled with amniotic fluid was removed and a disposable and absorbent pre-weighed linen saver sheet $(90 \mathrm{~cm} \times 60 \mathrm{~cm})$ was placed under the patient's buttocks to collect the blood from the uterine cavity. Depending on the situation, some patients needed more than one sheet, and then, this addition was considered in the final calculation of the total blood loss.

The placenta was delivered by controlled cord traction immediately after the delivery of the neonate to avoid iatrogenic placental entrapment, and the duration of the third stage of labor was noted. Placenta and membranes were examined for completeness of removal. After documentation of a well contracted uterus, blood clots, if any, were expressed from the vagina into the sheet, which was then removed and weighed. A fresh pre-weighed sanitary napkin was applied. Separate swabs, not included in the final calculation, were used for episiotomy site, if present.

Two hours after delivery, the pre-weighed, blood-soaked linen saver sheets and pre-weighed sanitary pads were weighed to assess maternal blood loss. For this issue, we used a sensitive digital balance (scale ERZ 20) with sensitivity up to 5 grams. The specific gravity of whole blood being 1.0506 at $37 \mathrm{C}^{\circ}$, each $\mathrm{ml}$ of blood was found to equal 1.05 grams. ${ }^{10}$ The equation was entered to the computer system to automatically calculate the amount of the blood loss. 
Standard postpartum instructions were given to the patient. The duration of the third stage, blood loss, and requirement of additional oxytocic drug and blood transfusion were compared among the 3 groups.

During patients recruitment and data entry, the data was stored by SQL server program which referred to as Structured Query Language, a database computer declarative language designed for managing data in relational database management systems (RDBMS). Its scope includes data insert, query, update and delete, schema creation and modification, and data access control.

After completeness of recruitment, data was processed and analyzed by SPSS version 22 .

Recruitment of patients was started after getting the final approval from the ethics committee of the Obstetrics and Gynecology council of the Sudan Medical Specialization Board. A written informed consent was obtained from each patient prior to joining the study. The study never interfered with hospital policies and labor ward guidelines. Confidentiality of patients' records were maintained. The patient who received blood transfusion was hospitalized for observation and discharged home safely after 48 hours.

\section{RESULTS}

Data were collected, sorted and analyzed for the 140 participants, where 47 of them received oxytocin, and 47 received Ergometrine and 46 received misoprostol. Table
1 showed age groups of less than 20 years, 20-29 years and 29-39 years constituted 5.7\%, 67.1\% and 27.25 respectively.

Table 1: Age and obstetric characteristics of the patients $(n=140)$.

\begin{tabular}{|lll|}
\hline Variable & Frequency & $\%$ \\
\hline Age/ years & & \\
\hline Less than 20 & 8 & 5.7 \\
\hline $20-29$ & 94 & 67.1 \\
\hline $30-39$ & 38 & 27.2 \\
\hline Parity & \\
\hline Primiparous & 40 & 28.6 \\
\hline Multiparous & 100 & 71.4 \\
\hline Gestational age & & \\
\hline 37-37 wks+6 days & 12 & 8.6 \\
\hline $38-38$ wks+6 days & 24 & 17.1 \\
\hline 39-39 wks+6 days & 28 & 20.0 \\
\hline $40-40$ wks+6 days & 60 & 42.9 \\
\hline $41-41$ wks+6 days & 16 & 11.4 \\
\hline
\end{tabular}

Normal distribution of age among the three study arms was $(27.02 \pm 1.52$ year) for oxytocin, compared to (25.72 \pm 1.42 year) for Ergometrine and (27.07 \pm 1.6 year) for misoprostol. Primiparous and Multiparous women were $28.6 \%$ and $71.4 \%$ respectively. Gestational age was, 37-37 weeks +6 days, 38-38 weeks +6 days, 39-39 weeks +6 days, 40-40 weeks +6 days and $41-41$ weeks + 6 days were $8.6 \%, 17.1 \%, 20.0 \%, 42.9 \%$ and $11.4 \%$ respectively.

Table 2: Means and significance for labor and birth characteristics.

\begin{tabular}{|c|c|c|c|c|}
\hline Characteristics & $\begin{array}{l}10 \text { IU Oxytocin } \\
(n=47)\end{array}$ & $\begin{array}{l}\text { 0,5 mg Ergometrine } \\
(\mathrm{n}=47)\end{array}$ & $\begin{array}{l}400 \mu \mathrm{g} \text { Misoprostol } \\
(\mathrm{n}=46)\end{array}$ & $\mathbf{P}$ value \\
\hline First stage/min & $388.83 \pm 42.11$ & $367.02 \pm 47.53$ & $380.65 \pm 37.17$ & 0.761 \\
\hline Second stage/ $\mathrm{min}$ & $25.6 \pm 3.71$ & $26.13 \pm 3.35$ & $25.72 \pm 3.23$ & 0.974 \\
\hline Third stage/min & $4.6 \pm 0.9$ & $5.45 \pm 0.9$ & $3.89 \pm 0.37$ & 0.004 \\
\hline Newborn weight/g & $2988.3 \pm 120.41$ & $3008.3 \pm 122.77$ & $2915.22 \pm 108.02$ & 0.498 \\
\hline Blood loss/ ml & $205.56 \pm 34.82$ & $214.49 \pm 35.97$ & $168.36 \pm 24.83$ & 0.002 \\
\hline
\end{tabular}

Means for the labor and birth characteristics including duration of labor and newborn weight are shown in (Table 2). Birth weight ranged from 2.3 to $4.3 \mathrm{~kg}$, where mean weight of newborns in the oxytocin arm was $(2988.3 \pm 120.41 \mathrm{~g})$, compared to $(3008.3 \pm 122.77 \mathrm{~g})$ for Ergometrine and $(2915.22 \pm 108.02 \mathrm{~g})$ for misoprostol. The difference was statistically insignificant between groups (ANOVA test, $\mathrm{P}=0.498$ ). Mean duration of the first stage of labor for oxytocin was $(388.83 \pm 42.11 \mathrm{~min})$, compared to $(367.02 \pm 47.53 \mathrm{~min})$ for Ergometrine and (380.65 $\pm 37.17 \mathrm{~min})$ for misoprostol. The difference was statistically insignificant between groups (ANOVA test,
$\mathrm{P}=0.761)$. Mean durations of the second stage of labor were $(25.6 \pm 3.71 \mathrm{~min}),(26.13 \pm 3.35 \mathrm{~min})$ and $(25.72 \pm 3.23$ min) for oxytocin, Ergometrine and misoprostol respectively. The difference was statistically insignificant between groups (ANOVA test, $\mathrm{P}=0.974$ ).

The shortest mean duration of the third stage of labor was seen in patients who received misoprostol $(3.89 \pm 0.37$ $\mathrm{min})$, followed by oxytocin $(4.6 \pm 0.9 \mathrm{~min})$, and Ergometrine $(5.45 \pm 0.9 \mathrm{~min})$. The difference in duration was statistically significant between groups (ANOVA test, $\mathrm{P}=0.004)$. Using the LSD test, there was significant statistical difference when comparing the mean duration 
of the third stage of labor of the misoprostol arm to that of Ergometrine $(\mathrm{P}=0.001)$, while the differences were insignificant when comparing oxytocin to both other arms as shown in Table 3.

Table 3: Difference in mean duration of third stage of labor in the three groups.

\begin{tabular}{|llll|} 
Drug & Drug & $\begin{array}{l}\text { Mean } \\
\text { difference }\end{array}$ & significance \\
\hline Oxytocin & Ergometrine & -0.851 & 0.064 \\
\hline Oxytocin & Misoprostol & 0.704 & 0.126 \\
\hline Ergometrine & Oxytocin & 0.851 & 0.064 \\
\hline Ergometrine & Misoprostol & 1.556 & 0.001 \\
\hline Misoprostol & Oxytocin & -0.704 & 0.126 \\
\hline Misoprostol & Ergometrine & -1.556 & 0.001 \\
\hline
\end{tabular}

The lowest mean blood loss was seen in the patients who received misoprostol $(168.36 \pm 24.83 \mathrm{ml})$, followed by those who received oxytocin $(205.56 \pm 34.82 \mathrm{ml})$, and Ergometrine $(214.49 \pm 35.97 \mathrm{ml})$. The difference in blood loss was statistically significant between all the groups (ANOVA test, $\mathrm{P}=0.002$ ). Using the LSD test, there were significant statistical differences when comparing the mean blood loss of the misoprostol arm to those of oxytocin $(\mathrm{P}=0.008)$, or ergometrine $(\mathrm{P}=0.001)$. While, the difference was insignificant when comparing oxytocin group with ergometrine group $(\mathrm{P}=0.525)$, this was shown in Table 4.

Table 4: Difference in mean blood loss in the three groups.

\begin{tabular}{|llll|} 
Drug & Drug & $\begin{array}{l}\text { Mean } \\
\text { difference }\end{array}$ & Significance \\
\hline Oxytocin & Ergometrine & -8.934 & 0.525 \\
\hline Oxytocin & Misoprostol & 37.195 & 0.008 \\
\hline Ergometrine & Oxytocin & 8.934 & 0.525 \\
\hline Ergometrine & Misoprostol & 46.13 & 0.001 \\
\hline Misoprostol & Oxytocin & -37.195 & 0.008 \\
\hline Misoprostol & Ergometrine & -46.13 & 0.001 \\
\hline
\end{tabular}

\section{DISCUSSION}

Although, labor should be a safe event and lead to a happy ending after a long journey of pregnancy, unfortunately it might turn into a tragedy when complicated by postpartum hemorrhage. There is a global trend toward minimizing the incidence of such catastrophes. So many international researches concerning this condition were published during the last few years, where data results were controversial in their conflict, but all of them admitted the importance of the active management of the third stage of labor.

According to age distribution in this study, we found that almost two thirds of patients were in their third decade. This is consistent with the fact that during this age group, ladies are in their highest fertility and sexual activity ${ }^{11}$.
The rate of distribution of patients was directly correlated to the advancing in the gestational age, until peaks at the $40-40+6$ week $(42.9 \%)$ then declines after.

These results might reflect the efficiency of the common practice of cervical sweeping at completed 40 weeks in this setting. On the other hand, the decline in presentation of patients after 41 weeks might reflect the increased awareness of the importance of the antenatal follow up both by patients and doctors, where at this gestational age the patient should have been induced.

It has been established during this trial that the sublingually administered misoprostol is more effective than intravenous oxytocin and Ergometrine, both in minimizing blood loss in the third stage of labor and in shortening of the duration of the third stage of labor. These results are consistent with another study done in New Delhi. ${ }^{12}$ The average blood losses in our study were $168.36 \mathrm{ml}, 205.56 \mathrm{ml}$, and $214.49 \mathrm{ml}$ for misoprostol, oxytocin, Ergometrine respectively which were greater when compared to their findings, where they reported $126.24 \mathrm{ml}, 154.7 \mathrm{ml}$, and $223.4 \mathrm{ml}$ for the same sequence. Doses and routes were similar in both studies concerning misoprostol, but for oxytocin and Ergometrine, we have used almost the double dose with the same route. These differences might be due to the dilution method we have used for the parenteral drugs, which was explained by Davies et al, where they found that the estimates of blood loss were significantly greater by $(65.6 \mathrm{ml}, \mathrm{P}=0.029)$ in the diluted infusion oxytocin compared to the bolus dose. $^{13}$

Another study was done in Bangladesh, where they used the same doses of misoprostol and oxytocin but with different routes of administration. ${ }^{14}$

Present findings were much less than theirs, where they reported that the mean blood loss for intramuscular oxytocin was $375 \mathrm{ml}$, and for oral misoprostol was 325.4 $\mathrm{ml}$. These results support the findings of Chong et al, that administration of misoprostol by different routes results in significantly different actions. ${ }^{15}$

Intravenous oxytocin and Ergometrine in the present study showed similar effectiveness without significant difference in mean blood loss or mean duration of the third stage of labor. These results are like the reports from Nigeria ${ }^{16}$. In fact, oxytocin achieved these results without any side effects compared with the Ergometrine.

The mean duration of the third stage of labor in our study was $3.89 \mathrm{~min}, 4.6 \mathrm{~min}, 5.45$ for misoprostol, oxytocin and Ergometrine respectively. This was a little bit shorter but comparable to the findings of Singh et al, Sultana et al and Orji et al. ${ }^{16-18}$ This difference might be due to the early intervention with controlled cord traction in our study to avoid iatrogenic placental entrapment. 
Present findings showed that shivering and fever were observed significantly in the misoprostol arm, while Ergometrine arm significantly showed unpleasant side effects like nausea, vomiting and elevated blood pressure. These results are consistent with other reports. ${ }^{12,14,16,17}$

11 cases $(7.85 \%$ of the study population), out of which 5 in the oxytocin arm $(45.5 \%), 5$ in the Ergometrine arm $(45.5 \%)$, and 1 in the misoprostol arm (9\%) were given extra uterotonics. Although we felt that the use of extrauterotonics was not absolutely indicated in most of these cases, as it seems to be a routine practice towards patients with uterine atony either with or without bleeding; these results were comparable to other reports. ${ }^{12,14,16}$

Only one patient $(0.71 \%$ of the study population $)$ had blood loss greater than $500 \mathrm{ml}$ (she was in the oxytocin arm), and she was the only one who needed blood transfusion in this study. These results were comparable to other report. ${ }^{14}$

\section{CONCLUSION}

In conclusion, present study showed that $400 \mu \mathrm{g}$ sublingual misoprostol was more effective than the conventional parenteral uterotonics in reducing the amount of blood loss during the third stage of labor and has comparable effect to that of 10 IU intravenous oxytocin in shortening the duration of third stage of labor. It also showed that the use of misoprostol reduces the need for extrauterotonics and blood transfusion.

\section{ACKNOWLEDGMENTS}

Authors would like to acknowledge the National Ribat University Hospital, Sudan for their support. Authors also extend thanks to all women who participated in this work.

\section{Funding: No funding sources}

Conflict of interest: None declared

Ethical approval: The study was approved by the Institutional Ethics Committee

\section{REFERENCES}

1. Abou Zahr C. Antepartum and postpartum hemorrhage. In Maurray CJL, Lopez AD, eds. Health Dimensions of Sex and Reproduction. Boston: Harvard University Press;1998:172-181.

2. Poggi BH. Postpartum hemorrhage and the abnormal puerperium. In DeCherney AH, Nathan L, Goodwin TM, Laufer N, eds. Current diagnosis and treatment. Tenth edition. USA: McGraw-Hill;2007:477-97.

3. B-Lynch C, Keith LG, Lalonde AB, Karoshi M, eds. Postpartum Hemorrhage. A comprehensive guide to evaluation, management and surgical intervention. UK: Sapiens Publishing;2006:2-44
4. Mohammed AA, Mohammed E, Elnour M, Ahmed S, Abdelfattah A, Ahmed F. Maternal mortality community-based survey in Kassala state-Estern Sudan. Int Gynaecol Obstet. 2009;107S2:S271.

5. Mohammed AA. Postpartum hemorrhage, hospital experience in high maternal mortality zone in Sudan. Int Gynaecol Obstet. 2009;107S2:S271.

6. Gohilcorresponding JT, Tripathi B. A Study to compare the efficacy of misoprostol, oxytocin, methylergometrine and ergometrine-oxytocin in reducing blood loss in active management of 3rd stage of labor. J Obstet Gynaecol India. 2011 Aug; 61(4):408-12.

7. Prendiville WJ, Elbourne D, McDonald S. Active vs. expectant management in the third stage of labour. Cochrane Database Systemat Rev. 2004;2:CD000007

8. Rogers J, Wood J, McCandlish R, Ayers S, Truesdale A, Elbourne D. Acive versus expectant management of third stage of labour: the Hinchingbrooke randomized controlled trial. Lancet. 1998;351:693-99

9. Singh G; Radhakrishnan G; Guleria K. Comparison of Sublingual Misoprostol, Intravenous Oxytocin, and Intravenous Methylergometrine in Active Management of the Third Stage of Labor. Obstet Anesthes Digest. 2011; 31(1):33.

10. Freise KJ, Widness JA, Veng-Pedersen $P$. Erythropoietic response to endogenous erythropoietin in premature very low birth weight infants. Pharmacol Experiment Therapeut. 2010;332:229-37.

11. Seli E, Agarwal A, eds. Fertility preservation. New York: Springer, 2012:226. Available at http://www.springer.com/la/book/9781441917829 Accessed on 1.10.2017.

12. Singh G, Radhakrishnan G, Guleria K. Comparison of sublingual misoprostol, intravenous oxytocin, and intravenous methylergometrine in active management of the third stage of labour. Int Gynaecol Obstet. 2009;107:130-4.

13. Davies G, Tessier J, Woodman M, Lipson A, Hahn P. Maternal hemodynamics after oxytocin bolus compared with infusion in the third stage of labor. Obstet Gynecol. 2005;105:294-9.

14. Sultana N, Khatun M. Misoprostol versus oxytocin in the active management of the third stage of labour. Bangladesh Coll Physic Surg. 2007;25:73-76

15. Chong YS, Chua S, Shen L, Arulkumaran S. Does the route of administration of misoprostol make a difference? Euro Obstet Gynecol Reprod Biol. 2004;113:191-8.

16. Orji E, Agwu F, Loto O, Olaleye O. A randomized comparative study of prophylactic oxytocin versus Ergometrine in the third stage of labor. Int Gynaecol Obstet. 2008;101:129-32.

Cite this article as: Rahim AYHA, Ounsa MAAGE, Albarakati RG, Mohamed EY, Abdalla SM.

Comparison between oxytocin, ergometrine and misoprostol in active management of the third stage of labour: a randomized controlled trial. Int J Reprod Contracept Obstet Gynecol 2018;7:2076-80. 